\title{
Prevention of contrast-induced acute kidney injury in patients undergoing percutaneous coronary intervention
}

\author{
Marco Legnazzi*, Federica Agnello*, Davide Capodanno \\ Division of Cardiology, A.0.U. Policlinico "G. Rodolico-San Marco," University of Catania, Catania, Italy
}

\author{
KEY WORDS \\ contrast-induced \\ acute kidney injury, \\ contrast-induced \\ nephropathy, \\ percutaneous \\ coronary intervention
}

\begin{abstract}
Intravascular administration of contrast media is an irreplaceable step of percutaneous coronary intervention. Since the latter is a very common procedure, contrast-induced acute kidney injury (CI-AKI) has become one of the most frequent causes of acute nephropathy, and a relevant prognostic impact of CI-AKI has been observed. Some patient comorbidities and procedural characteristics have been identified as key risk factors of CI-AKI. In this review, we discuss current evidence and future research directions on CI-AKI prevention in patients undergoing percutaneous coronary intervention.
\end{abstract}

Introduction Percutaneous coronary intervention (PCI) is a widely performed procedure that requires the administration of iodinated contrast media (ICM) ${ }^{1,2}$ Therefore, patients undergoing PCI are at risk of contrast-induced acute kidney injury (CI-AKI), which is potentially associated with serious adverse clinical outcomes, including death. ${ }^{3}$ The aim of this article was to summarize current knowledge and new approaches to CI-AKI prevention in patients undergoing PCI.

Contrast-induced acute kidney injury: definition, epidemiology, pathophysiology, and risk factors Definition Contrast-induced acute kidney injury is the acute decline in renal function after exposure to ICM, which may occur in the absence of an alternative etiology after either diagnostic or therapeutic procedures (eg, computed tomography, coronary angiography, and PCI). Although several CI-AKI definitions have been proposed, a broadly accepted one includes an absolute serum creatinine increase of $0.3 \mathrm{mg} / \mathrm{dl}$ ( $26.5 \mu \mathrm{mol} / \mathrm{l})$ or higher within 48 hours after exposure to ICM or a $50 \%$ or more relative increase from baseline within 7 days. ${ }^{4}$

Epidemiology Differences in study definitions and patient characteristics explain the variable incidence of CI-AKI reported in the literature. In a large United States study of patients undergoing PCI published in 2004, CI-AKI was reported in $13.1 \% .^{5}$ In another nationwide study encompassing PCI procedures between 2009 and 2011, CI-AKI was reported in 7.1\%. ${ }^{6}$ Incidence of CI-AKI among 585 patients undergoing coronary angi-

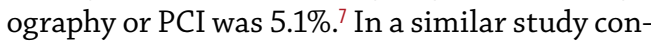
ducted in patients with acute coronary syndrome, CI-AKI was observed in $6 \%$ to $15.7 \%$, according to 3 different CI-AKI definitions. ${ }^{8}$ It is uncertain whether such heterogeneity depends on study differences or improvements in CI-AKI prevention.

Pathophysiology A causal relationship between ICM administration and renal damage is hard to establish from a mechanistic standpoint. Also, it has been suggested that ICM represents just a trigger to renal impairment. ${ }^{9,10}$ Consistently, a recent study showed no differences in CI-AKI rates in patients with ST-segment elevation myocardial infarction between those treated by primary PCI and those treated with thrombolysis, which does not need ICM. ${ }^{9}$ The multifactorial pathogenesis of CI-AKI may depend on pre-existing comorbidities and involve periprocedural factors other than ICM, including hypotension, bleeding, and plaque embolization. For this reason, a revised term has 
(1) Clinical setting

- Urgency/emergency

- Shock

- Nephrotoxic drugs

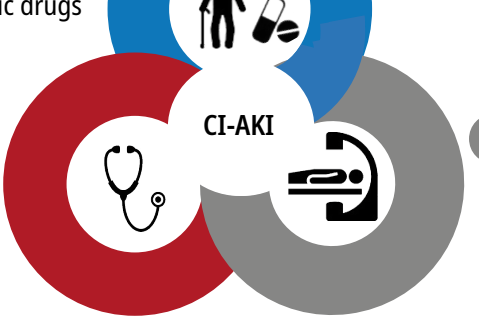

2

Patient

- Age $>75$ years

- Chronic kidney disease

- Diabetes mellitus

- Heart failure

- Anemia

Procedural aspects

- Contrast media type

- Contrast media volume

- Access

- IABP

FIGURE 1 Risk factors for contrast-induced acute kidney injury. Main CI-AKI contributors can be identified at 3 levels: clinical setting, patient conditions, and procedural aspects.

Abbreviations: IABP, intra-aortic balloon pump

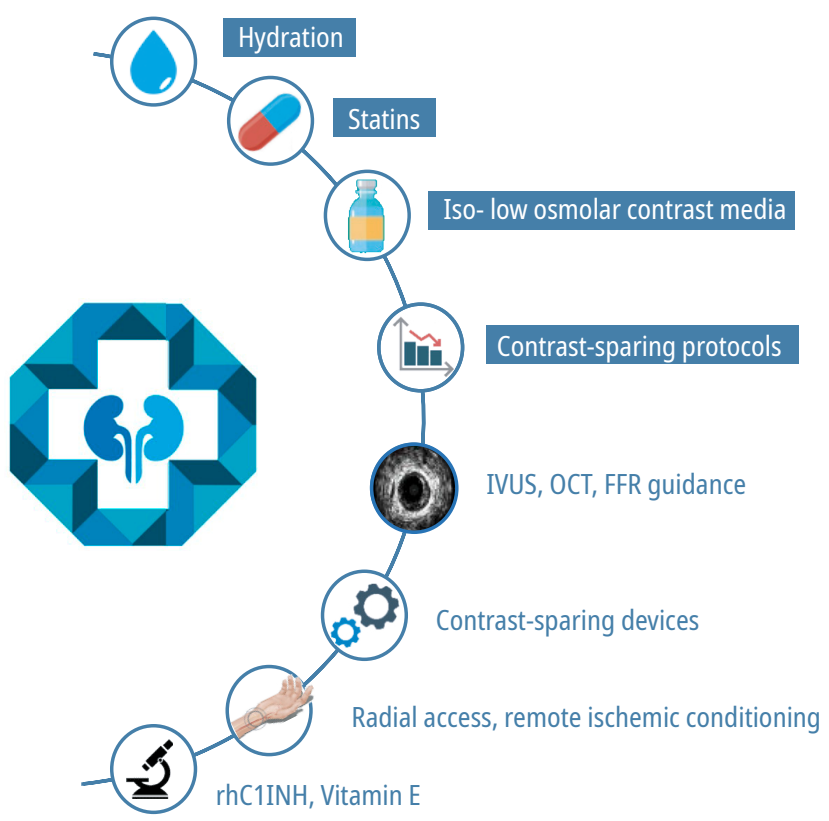

FIGURE 2 Present and experimental strategies for the prevention of contrast-induced acute kidney injury: guidelines recommended measures (blue highlight) as well as contrast-sparing devices and additional procedural approaches and future perspectives (blue font).

Abbreviations: IVUS, intravascular ultrasound; FFR, fractional flow reserve; OCT, optical coherence tomography; rhC1INH, recombinant human C1 inhibitor

been proposed, that is, contrast-associated acute kidney injury. It is thought that ICM provoke 2 types of damage, direct and indirect. Direct toxicity on tubular cells is carried out by free radicals and reactive oxygen species (ROS), generated by ICM, inducing apoptosis and osmotic nephrosis; moreover, the increased viscosity of tubular fluid could lead to tubular obstruction and injury. Indirect toxicity is due to ischemia of the outer medulla, caused by a disproportionate release of vasoconstrictive molecules (endothelin, prostaglandins, renin, angiotensin). ${ }^{11,12}$

Risk factors and predictive scores In preliminary risk assessment, numerous conditions should be considered that directly or indirectly impact renal function (FIGURE 1). 5,11,12 Obviously, the risk increases in case of multiple coexisting conditions. ${ }^{13}$ The Mehran score estimates the risk of CI-AKI by means of predictors that overlap with other commonly used tools such as the $\mathrm{Na}$ tional Cardiovascular Data Registry (NCDR) Cath-PCI AKI risk model. ${ }^{5,6,14}$ The main practical limitation of these scores is the inclusion of variables that are unknown until the end of the procedure. ${ }^{6}$ Independent predictors of CI-AKI that have been frequently demonstrated are ICM volume, ${ }^{5}$ diabetes mellitus, and advanced chronic kidney disease (CKD) (ie, estimated glomerular filtration rate $\left.[\mathrm{eGFR}]<30 \mathrm{ml} / \mathrm{min} / 1.73 \mathrm{~m}^{2}\right) .{ }^{6} \mathrm{In}$ terestingly, the complexity of PCI (eg, 3 vessels treated, $\geq 3$ stents implanted, 2-stent bifurcation intervention) does not play a role when adjusted for those risk factors. ${ }^{15}$

Clinical outcomes and prognosis of contrast-induced acute kidney injury Most patients with CI-AKI will experience only temporary impairment of renal function 24 to 48 hours after the procedure, with serum creatinine and diuresis returning to baseline values usually after 7 to 10 days. ${ }^{16-18}$ Nevertheless, a substantial number of studies reported that CI-AKI is associated with a higher risk of short-term and long-term adverse clinical outcomes., ${ }^{3,19-23}$ Many of these studies have no adjustment for baseline risk factors and may overestimate the increase in hospital stay and mortality that is truly the effect of renal impairment. Moreover, there are substantial differences across studies in the incidence of short and long-term adverse clinical events, likely because of their different methodology and lack of a standardized CI-AKI definition. In a PCI study of 5516 patients, after adjustment for confounders, CI-AKI was not significantly associated with higher 1-year mortality. ${ }^{24}$ A meta-analysis showed consistent results. ${ }^{25}$ Based on the above, it is difficult to establish if CI-AKI plays a main pathogenic role or is just a marker of higher risk for adverse clinical outcomes.

Prevention of contrast-induced acute kidney injury When CI-AKI occurs, no specific treatment is available. Therefore, prevention is key, including medical strategies (ie, hydration and drug administration) and procedural precautions and interventions (FIGURE2).

Hydration and drugs Most recent recommendations from the European and US guidelines on the prevention of CI-AKI after PCI are displayed in TABLE 1. Hydration is the cornerstone of preventive care, especially in patients with advanced and end-stage CKD.1,2 Conversely, the vast majority of investigational medications, with the exception of statins, achieved inconsistent results.

Isotonic saline Administration of standard isotonic saline $(0.9 \% \mathrm{NaCl})$ as an intravascular volume expansion strategy aims at protecting 
TABLE 1 Recommendations from the European and United States guidelines for the prevention of contrast-induced acute kidney injury

\begin{tabular}{|c|c|c|c|c|}
\hline \multirow[t]{2}{*}{ Strategy } & \multicolumn{2}{|c|}{2018 ESC guidelines on myocardial revascularization } & \multicolumn{2}{|c|}{2011 ACC / AHA/SCAI guidelines on PCI } \\
\hline & Regimen & $\begin{array}{l}\text { Class of recommendation } \\
\text { and level of evidence }\end{array}$ & Regimen & $\begin{array}{l}\text { Class of recommendation } \\
\text { and level of evidence }\end{array}$ \\
\hline \multirow{3}{*}{$\begin{array}{l}\text { Isotonic saline } \\
\text { hydration }\end{array}$} & - Adequate hydration & $\cdot$ IC & \multirow{3}{*}{$\begin{array}{l}\text { - } 1-1.5 \mathrm{ml} / \mathrm{kg} \text { per hour for } \\
3-12 \mathrm{~h} \text { before the procedure } \\
\text { and continuing for } 6-24 \mathrm{~h} \\
\text { after the procedure. } \\
\text { - Intravenous hydration is } \\
\text { preferable to oral hydration. }\end{array}$} & \multirow[t]{3}{*}{ IB } \\
\hline & \multirow{2}{*}{$\begin{array}{l}\text { - } 1 \mathrm{ml} / \mathrm{kg} \text { per hour } 12 \text { hours } \\
\text { before and continuing for } 24 \\
\text { hours after the procedure; } \\
0.5 \mathrm{ml} / \mathrm{kg} / \mathrm{h} \text { if LVEF } \leq 35 \% \text { or } \\
\mathrm{NYHA}>2 .^{\mathrm{a}} \text { This regimen } \\
\text { should be considered if } \\
\text { the expected contrast } \\
\text { volume is }>100 \mathrm{ml}\end{array}$} & \multirow[t]{2}{*}{ - IIa C } & & \\
\hline & & & & \\
\hline $\begin{array}{l}\text { Tailored isotonic } \\
\text { saline hydration }\end{array}$ & $\begin{array}{l}\text { Infusion rates adjusted to LV } \\
\text { end-diastolic pressure or } \\
\text { furosemide with matched } \\
\text { infusion of normal saline }\end{array}$ & IIb B & Not mentioned & - \\
\hline $\begin{array}{l}\text { Minimization } \\
\text { of contrast media } \\
\text { volume }\end{array}$ & $\begin{array}{l}\text { Recommended; ratio of total } \\
\text { contrast volume to GFR must } \\
\text { be }<3.7^{\text {a }}\end{array}$ & IB & Recommended & IB \\
\hline $\begin{array}{l}\text { Administration of low- } \\
\text {-osmolar or iso- } \\
\text {-osmolar contrast } \\
\text { media }\end{array}$ & Recommended ${ }^{\mathrm{a}}$ & I A & $\begin{array}{l}\text { Insufficient data to justify } \\
\text { specific recommendations }\end{array}$ & - \\
\hline Statins & $\begin{array}{l}\text { Pretreatment with } \\
\text { rosuvastatin } 40 / 20 \mathrm{mg} \text { or } \\
\text { atorvastatin } 80 \mathrm{mg}^{\mathrm{a}}\end{array}$ & IIa A & Not mentioned & - \\
\hline $\mathrm{N}$-acetylcysteine & Not mentioned & & Not useful & III A \\
\hline \multirow[t]{2}{*}{$\begin{array}{l}\text { Prophylactic } \\
\text { hemofiltration }\end{array}$} & $\begin{array}{l}\text { - Fluid replacement rate } \\
1000 \mathrm{ml} / \mathrm{h} \text { without negative } \\
\text { loss, starting } 6 \mathrm{~h} \text { before } \\
\text { the procedure }\end{array}$ & \multirow[t]{2}{*}{ IIb B } & \multirow[t]{2}{*}{ Not mentioned } & \\
\hline & $\begin{array}{l}\text { - May be considered before } \\
\text { complex PCI in patients with } \\
\text { NKF stage } 4 \text { CKD. }\end{array}$ & & & \\
\hline
\end{tabular}

a Recommendations for patients with advanced chronic kidney disease (National Kidney Foundation stages 3b and 4)

Abbreviations: ACC, American College of Cardiology; AHA, American Heart Association; CKD, chronic kidney disease; ESC, European Society of Cardiology; GFR, glomerular filtration rate; LVEF, left ventricular ejection fraction; NKF, National Kidney Foundation; NYHA, New York Heart Association; PCI, percutaneous coronary intervention; SCAI, Society for Cardiovascular Angiography and Interventions

the kidneys from direct and indirect ICM-induced damage. In 3 trials of primary PCI, periprocedural hydration with isotonic saline significantly reduced the rate of CI-AKI and improved short-term clinical outcomes. ${ }^{26-28} \mathrm{Par}$ ticularly in patients with congestive heart failure, hemodynamic-guided hydration is preferable. In the POSEIDON (Prevention of Contrast Renal Injury With Different Hydration Strategies) study, including 396 patients undergoing cardiac catheterization with an eGFR of $60 \mathrm{ml} / \mathrm{min} / 1.73 \mathrm{~m}^{2}$ or less, administration of normal saline guided by left ventricular end-diastolic pressure significantly reduced the rate of CI-AKI and major adverse clinical events at 6 months compared with standard fluid administration (6.7\% vs $16.3 \%$, respectively; $P=0.005){ }^{29}$ Qian et $\mathrm{al}^{30}$ obtained a similar result in a randomized study that compared central venous pressure-guided hydration as compared with standard hydration in 264 patients with CKD and congestive heart failure $(15.9 \%$ vs $29.5 \%$, respectively; $P=0.006)$. At variance with these studies, the AMACING (A Maastricht ContrastInduced Nephropathy Guidelines Study) trial, conducted in 660 patients with an eGFR of 30 to $59 \mathrm{ml} / \mathrm{min} / 1.73 \mathrm{~m}^{2}$, showed that no prophylaxis was noninferior to guideline-guided hydration protocols for CI-AKI prevention. ${ }^{31}$ Additionally, no differences in mortality or need for dialysis was reported at 1-year between groups. ${ }^{32}$ It should be emphasized that only $48 \%$ of patients in the AMACING trial received intra-arterial ICM. In addition, the trial had other limitations, including a broad noninferiority margin. Interestingly, a pairwise ( $\mathrm{n}=538$ patients) and network ( $n=1754$ patients) meta-analysis found that in patients undergoing coronary angiography or PCI there was no difference in CI-AKI between intravenous hydration and oral hydration. ${ }^{33}$ Patients included in this meta-analysis had an eGFR higher than $30 \mathrm{ml} / \mathrm{min} / 1.73 \mathrm{~m}^{2}$, meaning that these results cannot be generalized to patients with advanced CKD. Isotonic 
saline $(0.9 \% \mathrm{NaCl})$ may be better than hypotonic saline $(0.45 \% \mathrm{NaCl})$, according to a study on 1620 patients undergoing PCI. ${ }^{34}$ In summary, hydration has been shown to decrease the incidence of CI-AKI in patients undergoing PCI, especially in the acute setting and using hemodynamic-guided protocols of administration. Also, there is some preliminary evidence that the absence of prophylactic hydration could be noninferior to hydration in patients with nonsevere CKD.

Sodium bicarbonate Urinary alkalization and impeding the formation of ROS with sodium bicarbonate has been frequently investigated for the prevention of CI-AKI. However, in a meta-analysis of 22 studies and 5686 patients, sodium bicarbonate was not superior to isotonic saline. ${ }^{35}$ In addition, in the CINSTEMI (Prevention of Contrast-induced Nephropathy in Patients With ST-Segment Elevation Myocardial Infarction Undergoing Primary Percutaneous Coronary Intervention) trial, sodium bicarbonate was not better than standard hydration in patients with ST-segment elevation myocardial infarction (STEMI) undergoing primary PCI. ${ }^{36}$ The PRESERVE (Prevention of Serious Adverse Events Following Angiography) trial, including 5177 patients with CKD and / or diabetes undergoing coronary or noncoronary angiography, also ended with neutral results $(9.5 \%$ vs $8.3 \%$; $P=0.13$ ) in both the overall cohorts and in the subgroup analysis of patients who underwent PCI. ${ }^{37,38}$

Furosemide with matched hydration (RenalGuard system) The RenalGuard system is a closed loop device that delivers intravenous fluids matched to diuresis. Intravenous boluses of normal saline and furosemide are usually administered at the beginning. Then, the hydration infusion rate is automatically adjusted to replace precisely the urine output. In a meta-analysis including patients undergoing coronary angiography, PCI, or transcatheter aortic valve implantation, the use of the RenalGuard system was associated with a lower incidence of CI-AKI ( $7.8 \%$ vs $21.4 \%$, respectively; $P<0.001)$ and renal replacement therapy ( $0.6 \%$ vs $3.5 \%$, respectively; $P=0.02$ ) compared with controls. ${ }^{39}$ In the REMEDIAL III (Renal Insufficiency Following Contrast MEDIA Administration Trial III), the RenalGuard system was superior to intravenous hydration guided by left ventricular end-diastolic pressure in reducing a composite of $\mathrm{CI}-\mathrm{AKI}$ and pulmonary edema ( $5.7 \%$ vs $10.3 \%$, respectively; $P=0.04$ ) in 708 patients undergoing coronary angiography or PCI with eGFR of $45 \mathrm{ml} / \mathrm{min} / 1.73 \mathrm{~m}^{2}$ or less and high risk scores for predicted kidney injury. ${ }^{40}$

$\mathrm{N}$-acetylcysteine Given its antioxidant properties, $\mathrm{N}$-acetylcysteine is thought to mitigate the detrimental action of ROS generated by ICM.
However, in the ACT (The Acetylcysteine for Contrast-Induced Nephropathy Trial), including 2308 patients undergoing coronary or peripheral angiography, $\mathrm{N}$-acetylcysteine did not decrease the risk of CI-AKI or other clinically relevant outcomes at 30 days. ${ }^{41}$ Consistently, in the previously mentioned CINSTEMI and PRESERVE trials, oral $\mathrm{N}$-acetylcysteine failed to reduce the rates of $\mathrm{CI}-\mathrm{AKI}^{36,37}$ and the rate of death, need for dialysis or persistent kidney dysfunction at 90 days. $^{37}$

Statins Statins have been hypothesized to lower the risk of CI-AKI given their pleiotropic antioxidant and anti-inflammatory action. Multiple trials and meta-analyses proved that statin pretreatment is effective in diminishing the risk of CI-AKI. ${ }^{42-45}$ Considering that high-dose statins are indicated for coronary atherosclerotic disease, a large portion of patients undergoing PCI will already have them prescribed for chronic use. The European guidelines suggest the use of atorvastatin in a dose of $80 \mathrm{mg} / \mathrm{d}$ or rosuvastatin in a dose of 20 or $40 \mathrm{mg} / \mathrm{d}^{1}$

Other drugs Numerous other therapies have been studied to reduce the risk of CI-AKI, frequently with inconclusive or unconvincing results (eg, $\mathrm{Na} / \mathrm{K}$ citrate supplementation, ascorbic acid, aminophylline, and theophylline). ${ }^{46-49}$

Procedural strategies Preventive procedural measures include strategies and devices aiming at minimizing the administration of an ICM and reducing $\mathrm{CI}-\mathrm{AKI}$ in combination with hydration.

Iso-osmolarity and low osmolarity contrast media Main factors of toxicity for an ICM are iodine atoms per particles (expressed by osmolality) and viscosity, which are inversely proportional. ${ }^{50,51}$ The use of high-osmolar contrast medium is associated with higher rates of CI-AKI, which sets the stage for the use of low-osmolar contrast medium (LOCM) and iso-osmolar contrast medium (IOCM), usually preheated to attenuate the effect of their high viscosity on renal tubules. ${ }^{52-54}$ Several studies investigated the effects of IOCM and LOCM providing mixed results. ${ }^{55-57}$ As such, there is no robust evidence so far to favor LOCM over IOCM, which are both suitable options in the United States and European guidelines. ${ }^{1,2}$

Intracoronary imaging and physiology The load of ICM plays a key role in CI-AKI, prompting investigations of contrast-sparing strategies that do not sacrifice image quality and procedure success. The MOZART (Minimizing Contrast Utilization with IVUS Guidance in Coronary angioplasty) trial demonstrated that PCI guided by intravascular ultrasound is feasible and effective in reducing the use of ICM by $33 \%$ compared to 
angiography-guided PCI. ${ }^{58}$ Optical coherence tomography is commonly performed with ICM, but images of sufficient quality may be obtained also with dextran..$^{59}$ Further studies are needed to establish the safety of dextran-based optical coherence tomography as a guide to PCI, and dissipate current concerns of potential nephrotoxicity. Fractional flow reserve and instantaneous wave-free ratio are also tools helpful in minimizing the use of ICM by appraising the hemodynamic significance of coronary lesions and the final result of PCI. ${ }^{60}$

Protocols minimizing iodinated contrast media A practical way to calculate a safe threshold of ICM is using the ratio of contrast volume to eGFR, which is associated with decreased CI-AKI when less than $2 .{ }^{61} \mathrm{~A}$ ratio of contrast volume to eGFR of less than 1 is part of the so-called ultra-low contrast coronary angiography approach. This concept, intended for patients with advanced CKD, also includes $50 \%$ dilution of ICM with normal saline, use of small diameter catheters (5-6 Fr) without side-holes, little volume per contrast injection, high frame rate (30 frames/s), avoiding "puff testing" of contrast, and the use of biplane angiography. Once the angiographic images have been acquired, PCI can be performed without ICM, guided by intravascular ultrasound and physiology. The intervention is driven by anatomical landmarks, additional guidewires used to create a metallic roadmap of the target vessel and its side branches, or a digital, dynamic roadmap; intravascular ultrasound is performed to characterize the lesion, the stent implantation site,$^{62}$ and finally to confirm procedural success or identify dissections, if any. A small contrast volume is necessary in case of doubts or clinical deterioration. Also, a transthoracic echocardiogram before and after the procedure is useful to ascertain the absence of new onset of pericardial effusion. In experienced hands, these approaches are safe and preserve the residual kidney function, ${ }^{60,63,64}$ but the risk of complications raises for lesions in small vessels.

Device-based interventions Automated contrast injector systems reduce ICM compared with manual injection, decreasing the incidence of CI-AKI by about $15 \% .{ }^{65,66}$ Devices designed for ICM modulation were also introduced, such as the DyeVert Plus Contrast Reduction System. The core of this tool is a pressure valve through which it diverts a part of ICM per manual injection to a reservoir chamber, reducing ICM reflux into the aortic root. ${ }^{67} \mathrm{~A}$ wireless display constantly monitors the volume administered. The ability to significantly reduce ICM was proven in the randomized AVERT (AVERT Clinical Trial for Contrast Media Volume Reduction and Incidence of CIN) but no differences in CI-AKI were reported. ${ }^{68}$ Potentially, the DyeVert system can be used in combination with automated contrast injector systems, with synergy of strength. Coronary sinus aspiration to reduce ICM was successfully tested, ${ }^{69,70}$ but the challenge of this approach limits its wide adoption. Finally, in patients with impaired heart function, the use of ventricular assistance devices, while improving renal perfusion, has been suggested to relieve the ischemic trigger and the incidence of CI-AKI after PCI, warranting further investigations. ${ }^{71}$

Other strategies Other strategies aim at reducing CI-AKI by preventing ischemic renal injury and beyond. Remote ischemic conditioning is a biological phenomenon resulting in protection of organs and tissues remote from the site where conditioning is applied, through complex mechanisms involving humoral factors, neuronal pathways, and anti-inflammatory response. ${ }^{72}$ In the RenPro-Trial, 100 patients with CKD undergoing elective coronary angiography were randomly allocated to standard procedure or the same with remote conditioning at the upper limb, alternating inflations and deflations of a manometer cuff before the procedure. The CI-AKI rates were significantly lower with remote conditioning. ${ }^{73}$ However, another trial applying the same preconditioning protocol in a similar cohort did not confirm these findings. ${ }^{74}$ In contrast, Deftereos et $\mathrm{al}^{75}$ found ischemic post-conditioning to be effective in a cohort of 225 patients with non-ST-elevation myocardial infarction undergoing PCI. The conditioning stimulus in this case was exerted after stenting the culprit lesion, by inflation and deflation of the stent balloon. Radial access has been also suggested to reduce $\mathrm{CI}-\mathrm{AKI}$. In fact, this vascular approach is associated with lower risk of cholesterol embolization to renal arteries and causes less major bleeding compared with femoral access, resulting in lower hemodynamic instability and CI-AKI, particularly in higher risk settings, such as STEMI. ${ }^{76}$ These speculations are consistent with the CI-AKI findings of the MATRIX-Access study conducted in 8210 patients randomized to trans-radial or trans-femoral PCI ( $15.4 \%$ vs $17.4 \%$, respectively; $P=0.02) .{ }^{77}$ Finally, discontinuation of nephrotoxic drugs such as nonsteroidal anti-inflammatory agents is a good precaution.

Future perspectives Several other promising strategies are currently under investigation, including administration of molecules like nicorandil, ${ }^{78,79}$ trimetazidine, ${ }^{80,81}$ and vitamin E. ${ }^{82}$

A recent proof-of-concept study with the recombinant human $\mathrm{C} 1$ esterase inhibitor yielded interesting results ${ }^{83}$; considering also its strong local complement inhibiting action, it could be particularly suitable for patients undergoing PCI, because during the procedure, embolization of 
cholesterol may cause mechanical occlusion and trigger complement-mediated inflammation, in the systemic and renal circulation. Another strategy that has attracted attention is bioimpedance vector analysis. This is a technique that allows a fast and noninvasive assessment of total body water that can be used easily to guide intravenous infusion of normal saline according to actual patient hydration status. ${ }^{84}$ Larger randomized studies are needed to support these drugs and approaches to CI-AKI prevention.

Conclusions CI-AKI is a complication of PCI that requires careful consideration and prevention. Adequate hydration and the parsimonious use of ICM are recommended in each case. Intracoronary imaging helps minimizing the use of ICM. Especially in high-risk procedures, preventive measures can be implemented through ICM-sparing devices, zero-contrast PCI, or hemodynamic support. Notably, other strategies such as ischemic conditioning and radial access have proven beneficial, and a deeper knowledge on the effects of ICM might lead to the development of new drugs for prevention and treatment in the future. At present, statins are the only pharmacological approach supported by good-quality evidence. Finally, consideration of individual circumstances and clinical scenarios is the key for tailoring CI-AKI preventive approaches.

\section{ARTICLE INFORMATION}

\section{CONFLICT OF INTEREST None declared.}

OPEN ACCESS This is an Open Access article distributed under the terms of the Creative Commons Attribution-NonCommercial-NoDerivatives 4.0 International License (CC BY-NC-ND 4.0), allowing third parties to download articles and share them with others, provided the original work is properly cited, not changed in any way, distributed under the same license, and used for noncommercial purposes only. For commercial use, please contact the journal office at kardiologiapolska@ptkardio.pl.

HOW TO CITE Legnazzi M, Agnello F, Capodanno D. Prevention of contrast-induced acute kidney injury in patients undergoing percutaneous coronary intervention. Kardiol Pol. 2020; 78: 967-973. doi:10.33963/KP.15537

\section{REFERENCES}

1 Neumann FJ, Sousa-Uva M, Ahlsson A, et al. 2018 ESC/EACTS Guidelines on myocardial revascularization. EuroIntervention. 2019; 14: 1435-1534.

2 Levine GN, Bates ER, Blankenship JC, et al. 2011 ACCF/AHA/SCAI quideline for percutaneous coronary intervention. J Am Coll Cardiol. 2011; 58: e44-e122.

3 McCullough PA, Wolyn R, Rocher LL, et al. Acute renal failure after coronary intervention: Incidence, risk factors, and relationship to mortality. Am J Med. 1997; 103: 368-375.

4 Kellum JA, Lameire N, Aspelin P, et al. KDIG0 clinical practice guideline for acute kidney injury. Kidney Int Suppl. 2012; 2: 1-138.

5 Mehran R, Aymong ED, Nikolsky E, et al. A simple risk score for prediction of contrast-induced nephropathy after percutaneous coronary intervention: development and initial validation. J Am Coll Cardiol. 2004; 44: 1393-1399.

6 Tsai TT, Patel UD, Chang TI, et al. Contemporary incidence, predictors, and outcomes of acute kidney injury in patients undergoing percutaneous coronary interventions: insights from the NCDR cath-PCI registry. JACC Cardiovasc Interv. 2014; 7: 1-9.

7 Morabito S, Pistolesi V, Benedetti G, et al. Incidence of contrast-induced acute kidney injury associated with diagnostic or interventional coronary angiography. J Nephrol. 2012; 25: 1098-1107.

8 Guillon B, Ecarnot F, Marcucci C, et al. Incidence, predictors, and impact on six-month mortality of three different definitions of contrast-induced acute kidney injury after coronary angiography. Am J Cardiol. 2018; 121: 818-824.

9 Caspi 0 , Habib M, Cohen Y, et al. Acute kidney injury after primary angioplasty: is contrast-induced nephropathy the culprit? J Am Heart Assoc. 2017; 6: 1-10.
10 Ehrmann S, Quartin A, Hobbs BP, et al. Contrast-associated acute kidney injury in the critically ill: systematic review and Bayesian meta-analysis. Intensive Care Med. 2017; 43: 785-794.

11 Azzalini L, Spagnoli V, Ly HQ. Contrast-induced nephropathy: from pathophysiology to preventive strategies. Can J Cardiol. 2016; 32: 247-255.

12 McCullough PA, Choi JP, Feghali GA, et al. Contrast-induced acute kidney injury. J Am Coll Cardiol. 2016; 68: 1465-1473.

13 Kirtane AJ, Doshi D, Leon MB, et al. Treatment of higher-risk patients with an indication for revascularization: evolution within the field of contemporary percutaneous coronary intervention. Circulation. 2016; 134: 422-431.

14 Gurm HS, Seth M, Kooiman J, Share D. A novel tool for reliable and accurate prediction of renal complications in patients undergoing percutaneous coronary intervention. J Am Coll Cardiol. 2013; 61: 2242-2248.

15 Azzalini L, Poletti E, Lombardo F, et al. Risk of contrast-induced nephropathy in patients undergoing complex percutaneous coronary intervention. Int J Cardiol. 2019; 290: 59-63.

16 Solomon R. Contrast-medium-induced acute renal failure. Kidney Int. 1998; 53: 230-242.

17 Liss $P$, Persson PB, Hansell P, Lagerqvist $B$. Renal failure in 57925 patients undergoing coronary procedures using iso-osmolar or low-osmolar contrast media. Kidney Int. 2006; 70: 1811-1817.

18 Teruel JL, Marcén R, Onaindía JM, Serrano A. Renal function impairment caused by intravenous urography. Arch Intern Med. 1981; 141: 1271

19 Bartholomew BA, Harjai KJ, Dukkipati S, et al. Impact of nephropathy after percutaneous coronary intervention and a method for risk stratification. Am J Cardiol. 2004; 93: 1515-1519.

20 Giacoppo D, Madhavan M V., Baber U, et al. Impact of contrast-induced acute kidney injury after percutaneous coronary intervention on short- and long-term outcomes. Circ Cardiovasc Interv. 2015; 8: e002 475.

21 Rihal CS, Textor SC, Grill DE, et al. Incidence and prognostic importance of acute renal failure after percutaneous coronary intervention. Circulation. 2002; 105: 2259-2264.

22 Gruberg L, Mintz GS, Mehran R, et al. The prognostic implications of further renal function deterioration within $48 \mathrm{~h}$ of interventional coronary procedures in patients with pre-existent chronic renal insufficiency. J Am Coll Cardiol. 2000; 36: 1542-1548. 23 Weisbord SD, Chen H, Stone RA, et al. Associations of increases in serum creatinine with mortality and length of hospital stay after coronary angiography. J Am Soc Nephrol. 2006; 17: 2871-2877.

24 Abe M, Morimoto T, Nakagawa Y, et al. Impact of transient or persistent contrast-induced nephropathy on long-term mortality after elective percutaneous coronary intervention. Am J Cardiol. 2017; 120: 2146-2153.

25 Coca SG, Zabetian A, Ferket BS, et al. Evaluation of short-term changes in serum creatinine level as a meaningful end point in randomized clinical trials. J Am Soc Nephrol. 2016; 27: 2529-2542.

26 Jurado-Román A, Hernández-Hernández F, García-Tejada J, et al. Role of hydration in contrast-induced nephropathy in patients who underwent primary percutaneous coronary intervention. Am J Cardiol. 2015; 115: 1174-1178.

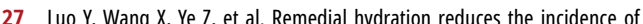
contrast-induced nephropathy and short-term adverse events in patients with ST-segment elevation myocardial infarction: a single-center, randomized trial. Intern Med. 2014; 53: 2265-2272.

28 Maioli M, Toso A, Leoncini M, et al. Effects of hydration in contrast-induced acute kidney injury after primary angioplasty. Circ Cardiovasc Interv. 2011; 4: 456-462.

29 Brar SS, Aharonian V, Mansukhani P, et al. Haemodynamic-guided fluid administration for the prevention of contrast-induced acute kidney injury: the POSEIDON randomised controlled trial. Lancet. 2014; 383: 1814-1823.

30 Qian G, Fu Z, Guo J, et al. Prevention of contrast-induced nephropathy by central venous pressure-guided fluid administration in chronic kidney disease and congestive heart failure patients. JACC Cardiovasc Interv. 2016; 9: 89-96.

31 Nijssen EC, Rennenberg RJ, Nelemans PJ, et al. Prophylactic hydration to protect renal function from intravascular iodinated contrast material in patients at high risk of contrast-induced nephropathy (AMACING): a prospective, randomised, phase 3, controlled, open-label, non-inferiority trial. Lancet. 2017; 389: 1312-1322.

32 Nijssen EC, Nelemans PJ, Rennenberg RJ, et al. Prophylactic intravenous hydration to protect renal function from intravascular iodinated contrast material (AMACING): Iong-term results of a prospective, randomised, controlled trial. EClinicalMedicine. 2018; 4-5: 109-116.

33 Zhang W, Zhang J, Yang B, et al. Effectiveness of oral hydration in preventing contrast-induced acute kidney injury in patients undergoing coronary angiography or intervention. Coron Artery Dis. 2018; 29: 286-293.

34 Mueller C, Buerkle G, Buettner HJ, et al. Prevention of contrast media-associated nephropathy: randomized comparison of 2 hydration regimens in $1620 \mathrm{pa}-$ tients undergoing coronary angioplasty. Arch Intern Med. 2002; 162: 329.

35 Zapata-Chica CA, Bello Marquez D, Serna-Higuita LM, et al. Sodium bicarbonate versus isotonic saline solution to prevent contrast-induced nephropathy: a systematic review and meta-analysis. Colomb Med. 2015; 46: 90-103.

36 Thayssen P, Lassen JF, Jensen SE, et al. Prevention of contrast-induced nephropathy with $\mathrm{N}$-acetylcysteine or sodium bicarbonate in patients with ST-segment-myocardial infarction. Circ Cardiovasc Interv. 2014; 7: 216-224. 
37 Weisbord SD, Gallagher M, Jneid $\mathrm{H}$, et al. Outcomes after angiography with sodium bicarbonate and acetylcysteine. N Engl J Med. 2018; 378: 603-614.

38 Garcia S, Bhatt DL, Gallagher M, et al. Strategies to reduce acute kidney injury and improve clinical outcomes following percutaneous coronary intervention: a subgroup analysis of the PRESERVE trial. JACC Cardiovasc Interv. 2018; 11: 2254-2261.

39 Putzu A, Boscolo Berto M, Belletti A, et al. Prevention of contrast-induced acute kidney injury by furosemide with matched hydration in patients undergoing interventional procedures: a systematic review and meta-analysis of randomized trials. JACC Cardiovasc Interv. 2017; 10: 355-363.

40 Briguori C; REMEDIAL III Investigators. Renal insufficiency following contrast media administration trial III: UFR-guided vs LVEDP-guided hydration in high-risk patients for contrast-induced acute kidney injury. Presented at the Transcatheter Cardiovascular Therapeutics meeting, San Francisco, California, United States. September 29, 2019.

41 ACT Investigators. Acetylcysteine for prevention of renal outcomes in patients undergoing coronary and peripheral vascular angiography: main results from the randomized Acetylcysteine for Contrast-induced nephropathy Trial (ACT). Circulation. 2011; 124: 1250-1259.

42 Zhang J, Guo Y, Jin Q, et al. Meta-analysis of rosuvastatin efficacy in prevention of contrast-induced acute kidney injury. Drug Des Devel Ther. 2018; 12: $3685-3690$

43 Liu LY, Liu Y, Wu MY, et al. Efficacy of atorvastatin on the prevention of contrast-induced acute kidney injury: a meta-analysis. Drug Des Devel Ther. 2018; 12: 437-444.

44 Giacoppo D, Capodanno D, Capranzano P, et al. Meta-analysis of randomized controlled trials of preprocedural statin administration for reducing contrast-induced acute kidney injury in patients undergoing coronary catheterization. Am J Cardiol. 2014; 114.

45 Thompson K, Razi R, Lee MS, et al. Statin use prior to angiography for the prevention of contrastinduced acute kidney injury: A meta-analysis of 19 randomised trials. EuroIntervention. 2016; 12: 366-374.

46 Markota D, Markota I, Starčević B, et al. Prevention of contrast-induced nephropathy with $\mathrm{Na} / \mathrm{K}$ citrate. Eur Heart J. 2013; 34: 2362-2367.

47 Sadat U, Usman A, Gillard JH, Boyle JR. Does ascorbic acid protect against contrast-induced acute kidney injury in patients undergoing coronary angiography: a systematic review with meta-analysis of randomized, controlled trials. J Am Coll Cardiol. 2013; 62: 2167-2175.

48 Dai B, Liu Y, Fu L, et al. Effect of theophylline on prevention of contrast-induced acute kidney injury: A meta-analysis of randomized controlled trials. Am J Kidney Dis. 2012; 60: 360-370.

49 Zang $H$, Zhang $Q$, Li X. Adenosine antagonists for prevention of contrast-induced nephropathy: a meta-analysis of randomized controlled trials with trial sequential analysis. Exp Ther Med. 2019; 18: 85-98.

50 Keaney JJ, Hannon CM, Murray PT. Contrast-induced acute kidney injury: how much contrast is safe? Nephrol Dial Transplant. 2013; 28: 1376-1383.

51 Seeliger E, Sendeski M, Rihal CS, Persson PB. Contrast-induced kidney injury: mechanisms, risk factors, and prevention. Eur Heart J. 2012; 33: 2007-2015.

52 Tumlin J, Stacul F, Adam A, et al. Pathophysiology of contrast-induced nephropathy. Am J Cardiol. 2006; 98: 14-20.

53 Jo SH, Youn T], Koo BK, et al. Renal toxicity evaluation and comparison between Visipaque (iodixanol) and Hexabrix (ioxaglate) in patients with renal insufficiency undergoing coronary angiography. the RECOVER study: a randomized controlled trial. J Am Coll Cardiol. 2006; 48: 924-930.

54 Aspelin P, Aubry P, Fransson S-G, et al. Nephrotoxic effects in high-risk patients undergoing angiography. N Engl J Med. 2003; 348: 491-499.

55 McCullough PA, Bertrand ME, Brinker JA, Stacul F. A meta-analysis of the renal safety of isosmolar iodixanol compared with low-osmolar contrast media. J Am Coll Cardiol. 2006; 48: 692-699.

56 Reed M, Meier $\mathrm{P}$, Tamhane UU, et al. The relative renal safety of iodixano compared with low-osmolar contrast media. a meta-analysis of randomized controlled trials. JACC Cardiovasc Interv. 2009; 2: 645-654.

57 Azzalini L, Vilca LM, Lombardo F, et al. Incidence of contrast-induced acute kidney injury in a large cohort of all-comers undergoing percutaneous coronary intervention: comparison of five contrast media. Int J Cardiol. 2018; 273: 69-73.

58 Mariani J, Guedes C, Soares P, et al. Intravascular ultrasound guidance to minimize the use of iodine contrast in percutaneous coronary intervention the M0ZART (minimizing contrast utilization with IVUS guidance in coronary angioplasty) randomized controlled trial. JACC Cardiovasc Interv. 2014; 7: 1287-1293.

59 Frick K, Michael TT, Alomar M, et al. Low molecular weight dextran provides similar optical coherence tomography coronary imaging compared to radiographic contrast media. Catheter Cardiovasc Interv. 2014; 84: 727-731.

60 Ali ZA, Galougahi KK, Nazif T, et al. Imaging- and physiology-guided percutaneous coronary intervention without contrast administration in advanced rena failure: a feasibility, safety, and outcome study. Eur Heart J. 2016; 37: 3090-3095.

61 Gurm HS, Dixon SR, Smith DE, et al. Renal function-based contrast dosing to define safe limits of radiographic contrast media in patients undergoing percutaneous coronary interventions. J Am Coll Cardiol. 2011; 58: 907-914.

62 Sacha J, Gierlotka M, Feusette P, Dudek D. Ultra-low contrast coronary angiography and zero-contrast percutaneous coronary intervention for prevention of contrast-induced nephropathy: step-by-step approach and review. Postep w Kardiol Interwencyjnej. 2019; 15: 127-136.

63 Sacha J, Gierlotka M, Lipski P, et al. Zero-contrast percutaneous coronary interventions to preserve kidney function in patients with severe renal impairment and hemodialysis subjects. Postep w Kardiol Interwencyjnej. 2019; 15: 137-142.

64 Sacha J, Feusette P. Zero-contrast percutaneous coronary intervention of saphenous vein graft in a patient with chronic renal failure. Postepy Kardiol Interwencyjnej. 2018; 14: 309-311.

65 Minsinger KD, Kassis HM, Block CA. Meta-Analysis of the effect of automated contrast injection devices versus manual injection and contrast volume on risk of contrast-induced nephropathy. Am J Cardiol. 2014; 113: 49-53.

66 Brosh D, Assali A, Vaknin-Assa H, et al. The ACIST power injection system reduces the amount of contrast media delivered to the patient, as well as fluoroscopy time, during diagnostic and interventional cardiac procedures. Int $]$ Cardiovasc Intervent. 2005; 7: 183-187.

67 Gurm HS, Mavromatis K, Bertolet B, et al. Minimizing radiographic contrast administration during coronary angiography using a novel contrast reduction system: a multicenter observational study of the DyeVertTM plus contrast reduction system. Catheter Cardiovasc Interv. 2019; 93: 1228-1235.

68 Mehran R, Faggioni M, Chandrasekhar J, et al. Effect of a contrast modulation system on contrast media use and the rate of acute kidney injury after coronary angiography. JACC Cardiovasc Interv. 2018; 11: 1601-1610.

69 Duffy SJ, Ruygrok P, Juergens (P, et al. Removal of contrast media from the coronary sinus attenuates renal injury after coronary angiography and intervention. J Am Coll Cardiol. 2010; 56: 525-526.

70 Diab OA, Helmy M, Gomaa Y, El-Shalakany R. Efficacy and safety of coronary sinus aspiration during coronary angiography to attenuate the risk of contrast-induced acute kidney injury in predisposed patients. Circ Cardiovasc Interv. 2017; 10:1-8.

71 Flaherty MP, Pant S, Patel S V, et al. Hemodynamic support with a microaxial percutaneous left ventricular assist device (Impella) protects against acute kidney injury in patients undergoing high-risk percutaneous coronary intervention. Circ Res. 2017; 120: 692-700.

72 Lim SY, Hausenloy DJ. Remote ischemic conditioning: from bench to bedside. Front Physiol. 2012; 3 .

73 Er F, Nia AM, Dopp H, et al. Ischemic preconditioning for prevention of contrast medium-induced nephropathy: randomized pilot RenPro Trial (Renal Protection Trial). Circulation. 2012; 126: 296-303.

74 Ghaemian A, Yazdani ], Azizi S, et al. Remote ischemic preconditioning to reduce contrast-induced acute kidney injury in chronic kidney disease: a randomized controlled trial. BMC Nephrol. 2018; 19: 1-7.

75 Deftereos S, Giannopoulos G, Tzalamouras V, et al. Renoprotective effect of remote ischemic post-conditioning by intermittent balloon inflations in patients undergoing percutaneous coronary intervention. J Am Coll Cardiol. 2013; 61: 1949-1955.

76 Andò G, Costa F, Trio 0 , et al. Impact of vascular access on acute kidney injury after percutaneous coronary intervention. Cardiovasc Revascularization Med. 2016; 17: 333-338

77 Andò G, Cortese B, Russo F, et al. Acute kidney injury after radial or femoral access for invasive acute coronary syndrome management: AKI-MATRIX. J Am Coll Cardiol. 2017; 69: 2592-2603.

78 Nawa T, Nishigaki K, Kinomura Y, et al. Continuous intravenous infusion of nicorandil for 4 hours before and 24 hours after percutaneous coronary intervention protects against contrast-induced nephropathy in patients with poor renal function. Int J Cardiol. 2015; 195: 228-234.

79 Fan Y, Wei Q, Cai J, et al. Preventive effect of oral nicorandil on contrast-induced nephropathy in patients with renal insufficiency undergoing elective cardiac catheterization. Heart Vessels. 2016; 31: 1776-1782.

80 Nadkarni GN, Konstantinidis I, Patel A, et al. Trimetazidine decreases risk of contrast-induced nephropathy in patients with chronic kidney disease: a meta-analysis of randomized controlled trials. J Cardiovasc Pharmacol Ther. 2015; 20: 539-546.

81 Ye Z, Lu H, Su Q, et al. Clinical effect of trimetazidine on prevention of contrast-induced nephropathy in patients with renal insufficiency: an updated systematic review and meta-analysis. Medicine (Baltimore). 2017; 96: e6059.

82 Cho MH, Kim SN, Park HW, et al. Could vitamin e prevent contrast-induced acute kidney injury? A systematic review and meta-analysis. J Korean Med Sci. 2017; 32: 1468-1473

83 Panagiotou A, Trendelenburg M, Heijnen IAFM, et al. A randomized trial of recombinant human $(1$-esterase-inhibitor in the prevention of contrast-induced kidney injury. JACC Cardiovasc Interv. 2020; 13: 833-842.

84 Maioli M, Toso A, Leoncini M, et al. Bioimpedance-guided hydration for the prevention of contrast-induced kidney injury: the HYDRA study. J Am Coll Cardiol. 2018: 71: 2880-2889. 